\title{
Yaşlıların Pandemi Sürecindeki Biyopsikososyal Etkilenimleri
}

\author{
Fatma HASTAOĞLU1 \\ Sivas Cumhuriyet Üniversitesi, Sağlık Hizmetleri MYO, Yaşlı Bakımı Programı, Sivas / Türkiye \\ ORCID ID: 0000-0001-8929-2860
}

\begin{abstract}
ÖZET
Covid-19 virüsü ilk olarak Çin'in Wuhan kentinde görülmüș ve Dünya Sağlık Örgütü (WHO) 11 Mart'ta pandemi ilan etmiștir. Pandemi süreci tüm dünyada bașta sağllk, ekonomi ve toplumsal hayatı etkileyen oldukça önemli bir krize neden olmuștur. Covid-19 pandemisi herkesi etkisi altına alan, gerek toplumsal gerekse bireysel anlamda hem fiziksel hem ruhsal hem de ekonomik açıdan önemli önemli kayıplar yaşanmasına neden olan bir halk sağ̆lı̆̆ sorunudur. Dezavantajlı grup olarak bilinen yaşlıların, özellikle yașlı bireylerin enfeksiyon riski açısından riskli olmaları, hem ekonomik (para çekme, faturaları ödeme vb.), hem sosyal (yiyecek içecek alma, güneşı ısı̆ğından faydalanma $v b$.) hem de sağlık gereksinimleri( ilaçların temini, sağlık kontrollerinin yapılması vb.) için desteğe ihtiyaç duyabilmeleri, sosyal izolasyon yașamaları, toplumsal açıdan dıșlanmaları, bilinmeyene karşı korku duymaları gibi pek çok neden pandemi sürecinin yaşlılardaki etkisini gözler önüne sermektedir. Evde kalıp dıșarı çıkamayan yașlılarda, fiziksel ve ruhsal gerilemelerin görülmesinin yanı sıra, korunma ve bakım gereksinimlerinde de belirgin bir artış görülmektedir. Pandemi sağlık sistemi üzerinde ciddi yük olușturduğunda ve kaynakların pandemideki tüm nüfusun gereksinimleri ile başa çıkmak için yeterli olmadığında, yaşın olumsuz bir faktör olabileceği yönündeki risk unutulmamalı ve tüm yaşlı insanların bu zamanlarda saygı ve sevgi ile tedavi edilmesi sağlanmalıdır. Bu nedenle, yasslıların pandemi sürecinden etkilenimlerinin erken dönemde tespit edilmesinin, hem bakım uygulamalarının düzenlenmesine, yaşlıların hastane yatışlarının azaltılarak, pandeminin kontrol altına alınabilmesine katkı sağlayacağı düşünülmektedir. Yaşlılardaki pandeminin olumsuz etkilerini azaltmak, bakım gereksinimlerini karşılamak, sosyal yaşama katılımlarını kesmeden koruyabilmek, onların bu acil, olağandışı ve zor durumda toplumsal saygınlığını devam ettirebilmelerini sağlamak pandemi farkındalığını artırmakla sağlanacaktır. Calıșmamız, bu farkındalığı sağlamak amacıyla planlanmıștır.
\end{abstract}

\section{MAKALE GEÇMISŞI}

Gelis 17 Ocak 2021

Kabul 14 Haziran 2021

ANAHTAR KELIMELER

Yaşli, pandemi, biyopsikososyal etkilenim, geriatri, gerontoloji, Covid19

\section{Biopsychosocial effects of older adults during the pandemic period}

\section{ABSTRACT}

Covid-19 virus was first seen in Wuhan, China and spread rapidly, WHO declared a pandemic on March 11. The pandemic process has caused a serious crisis all over the world. Covid-19 pandemic is a problem that affects everyone and causes significant losses both socially and personally, physically, mentally and economically. Many reasons such as the older adults, who are the disadvantaged group, being risky in terms of infection risk, needing support for both economic, social and health needs, social isolation, social exclusion, fear of the unknown, show the effect of the pandemic process on the older adults. In addition to physical and mental regressions, there is a significant increase in the need for protection and care in the older adults who cannot leave the house. It is necessary to reduce the negative effects of the pandemic in the older adults, to meet their care needs, to protect their participation in social life without interrupting them, and to ensure that they maintain their social dignity in this normal situation. When the pandemic puts a burden on the healthcare system and resources are not sufficient to cope with the needs of the entire population in the pandemic, the risk that age can be a negative factor should not be forgotten, and all older people should be treated with respect and love at these times. For this reason, knowing the effects of the older adults from the pandemic process will contribute to the regulation of care practices and to control the pandemic by reducing hospitalizations of the older adults. To reduce the negative effects of the pandemic in the elderly, to meet their care needs, to protect their participation in social life without interrupting them, to ensure that they can maintain their social dignity in this urgent, extraordinary and difficult situation will be provided by increasing pandemic awareness. This study has been planned to raise this awareness.

\section{ARTICLE HISTORY}

Received 17 January 2021 Accepted 14 June 2021

\section{KEYWORDS}

Older adults, pandemic, biopsychosocial influence, geriatrics, gerontology, Covid-19

\footnotetext{
${ }^{1}$ Sorumlu Yazar: fhastaoglu@cumhuriyet.edu.tr
}

Makalenin Kaynak Olarak Gösterimi: Hastaoğlu, F. (2021). Yaşlıların pandemi sürecindeki biyopsikososyal etkilenimleri. Yaşlı Sorunları Araştırma Dergisi (YSAD) / Elderly Issues Research Journal (EIRJ), 14(1), 45-49. doi: 10.46414/yasad.863017 


\section{GİRIŞ}

Kovid-19 ciddi akut solunum yolu enfeksiyonlarına sebep olan ölümcül bir hastalıktır (Zhou, Yang, Lou, Wang, Hu, Zhang, Zhang \& Shi, 2020). Din, dil, ırk ya da cinsiyet ayrımı yapmayan bu hastalıkla ilgili olarak Dünya Sağlık Örgütü 30 Ocak 2020 tarihinde salgının halk sağlığı açısından uluslararası düzeyde endișe oluşturduğunu ve acil durum gerektirdiğini açıklamıştır Günümüzde Covid-19 pandemisi tüm dünyayı hızla etkisi altına almıştır. Enfeksiyonun insandan insana bulaştığı ve özellikle ileri yaș hastaların bu enfeksiyondan daha ciddi etkilenimleri olduğu belirlenmiștir (Ekici, 2020). Kovid-19 salgınında en önemli risk grubunu oluşturan yaşlı bireyler için bir takım tedbirler alınmıştır. $\mathrm{Bu}$ tedbirlerden önemli birisi de içișleri Bakanlığının 21 Mart 2020 tarihinde 81 il valiliğine gönderdiği genelge ile 65 yaş ve üstü vatandaşlar ile kronik rahatsızlığı bulunan kişilerin ikametlerinden dışarı çıkmalarının; park ve bahçe gibi açık alanlarda dolaşmalarının sınırlandırılması olmuştur (İçişleri Bakanlığı Genelgesi, 2020).

Dünyada ve ülkemizde yaşlı nüfus hızla artmaktadır. Artan yaşlı nüfusun pandemideki etkilenimleri üzerine literatürde pek çok tanımlayıcı çalışma olmasına karşın, yaşlıların biyopsikososyal boyutları ile bütüncül değerlendirilerek çok yönlü bir yaklaşımın gerekliliği açıktır. Bu çalışmada çok yönlü bir bakış açısıyla yaşlının tüm etkilenimlerinin belirlenmesi, bunun yanı sıra yaşlıların toplumsal saygınlığını devam ettirebilmelerini sağlamak için pandemi farkındalığının artırılması amaçlanmıştır.

\section{COVID-19 PANDEMISİ}

Koronavirüs (CoV), soğuk algınlığından Orta Doğu Solunum Sendromu (MERS-CoV) ve Ağır Akut Solunum Sendromu (Severe Acute Respiratory Syndrome, SARS$\mathrm{CoV})$ gibi daha ciddi hastalıklara kadar çeşitli hastalıklara neden olan büyük bir virüs ailesidir (Altın, 2020). Reseptör bağlayan gen bölgesinin yapısı, SARS koronavirüsüne çok benzer olduğu ve virüsün hücre girişi için aynı reseptörü, anjiyotensin dönüştürücü enzim 2'yi (ACE2) kullandığı gösterilmiștir (Zhou vd., 2020). Uluslararası Virüs Taksonomisi Komitesi Koronavirüs Çalışma Grubu, bu virüsün ciddi akut solunum sendromu koronavirüs 2 (SARS-CoV-2) olarak adlandırılmasını önermiștir (Applegate \& Ouslander, 2020). İlk olarak Aralık 2019'da Çin'in Wuhan kentinde belirlenmiş, daha önce insanlarda tanımlanmamış bir virüs olarak da Covid-19 şeklinde isimlendirilmiştir (Altın, 2020). Birçok enfeksiyon etkeni farklı bulaş yolları ile salgınlara yol açabilir. Bu salgın hastalıklar etkenin virülansına bağlı olarak zamanla kendi kendini sınırlandırabilir. Ancak, yüksek enfektiviteye bağlı kısa ya da uzun periyotlu etkiler de ortaya çlkarabilir (Kaya, 2020).

Başlangıçta koronavirüs olgularının büyük çoğunluğu Çin'den bildiriliyor olsa da, hastalık Çin dışında birçok ülkeyi etkilemiş ve olgu sayısında hızlı bir artış görülmüștür (Kara \& Alsancak, 2020). Günümüz verilere göre ise hem Avrupa hem de ABD salgının en fazla görüldügü bölgelerdendir. WHO raporuna göre, Covid-19'dan ölümlerin \% 89'u 65 yaş ve üstü kişilerde görülmektedir (WHO, 2020).
Pandemi süreci tüm yaş gruplarını etkiliyor olmasına rağmen, kırılgan gruplardaki etkilenimler çok daha ölümcül olabilmektedir. $\mathrm{Bu}$ sürecin belirli yaş gruplarına özgü olarak daha spesifik ele alınması, etkilenen grupların çok yönlü değerlendirilmeleriyle mümkün olacaktır.

\subsection{Yaşlılık Süreci ve Pandemide Yaşlllık}

WHO, yaşlılık tanımlamasına göre yaşlılar; 65-74 Yaş Genç Yaşlı, 75-84 yaş- Orta yaşlı ve 85 ve üzeri yaş- İleri Yaşlılık olarak belirlenmiștir (WHO, 2018). Tüm dünyada ve ülkemizde yaşlı nüfus giderek artmaktadır. Nüfus sayımlarına göre 2019 yılı için dünya nüfusunun yaklaşık 7,5 milyar, yaşlı nüfusun ise 700 milyon olduğu saptanmıştır. Türkiye İstatistik Kurumu (TÜİK) 2019 sonuçlarına göre ise, ülkemizde 65 ve daha yukarı yaştaki nüfus 5 yılda \% 21,9 artarak, geçen yıl 7 milyon 550 bin kişiye ulaşmıştır. Yaşlı nüfusun toplam nüfus içindeki oranının 2030 yılında \% 12,9'a yükseleceği ve 2080 yllına gelindiğinde ise ülke nüfusunun $1 / 4$ 'inin $(\% \quad 25,6)$ yașlı olacağı öngörülmektedir (TÜIK, 2018).

Ülkemizde ilk vaka 11 Mart 2020 tarihinde bildirilmiş, ilk ölümler (mortalite) ise yaşlı ve kronik hastalığa sahip bireylerden gelmiştir (Sağllk Bakanlığı, 2020a). Covid-19 enfeksiyonunun insandan insana bulaştı̆̆ı, özellikle yetișkinlerin Covid-19'a duyarlı olduğu ve hastalığın ciddiyetinin yaşla ilişkisi olduğu gösterilmiștir. DSÖ Avrupa bölgesi haftalık sürveyans verisine göre Covid-19 görülme sıklığı ve ölüm oranlarının özellikle 65 yaşından sonra arttığ bildirilmiștir (Ekici, 2020). Covid-19 görülme șiddeti ve yașı her yașta olabilmesine rağmen, ağırlıklı olarak ileri yaş ve altta yatan tıbbi komorbidite olan (kardiyovasküler hastalıklar, diyabetes mellitus, hipertansiyon, kronik akciğer hastalığı, kanserler, kronik böbrek yetmezliği, obezite ve sigara kullanımı) yetişkinlerde görülür (Zhou et al., 2020).

Pandemi öncesine bakıldığında, yașlı nüfus ölüm nedenleri arasında ülkemizde ve dünyada ilk sırada kronik hastalıklar yer almaktayken, günümüz pandemisinin, bu sıralamada yaratacağı değişiklik henüz öngörülememektedir. $\mathrm{Bu}$ anlamda pandemi sürecindeki yaşlılar, biyopsikososyal boyutlarıyla değerlendirilerek, fizyolojik, psikolojik ve sosyal yönden etkilenimleri incelenmelidir (Sağlık Bakanlığı, 2020a).

Yaşlılık, pek çok etken göz önüne alındığında pandemiden etkilenen önemli bir gelişimsel evre olarak dikkati çekmektedir. Pandemide korunma ise eldeki en güçlü silah olarak konuşulmaktadır. Korunma süreci için de sosyal mesafe maske ve hijyen kuralları üç temel başlık ön plana çıkmaktadır (Sağlık Bakanlığı, 2020a).Yaşlılarda ise sosyal mesafenin korunması, mental düzeylerindeki değișimlere bağlı güçleşebilmektedir. Bunun yanı sıra solunum problemi çekebilen, iletișim güçlüğü çeken yașlıların maske kullanımları da oldukça sıkıntı verici olabilmektedir (Oflaz, 2020). Hijyen için ise, yaşlılık döneminde kişisel bakım ihtiyaçlarının sürdürülmesinde yaşanan yetersizlikler pandeminin üç önemli kuralını uygulamada yașlılar için ciddi tehlikeler oluşturmaktadır (Sağlık Bakanlığı, 2020b). 
Tüm bu bilgiler ıșığında maske mesafe hijyen kurallarına uymakta zorluk çeken grup olan yaşlıların pandemi sürecinden ciddi oranda etkilenmeleri de kaçınılmazdır.

\subsection{Yaşlılardaki Fizyolojik Etkilenimler}

Yașlanma sürecini; kalıtımsal faktörler, yașam biçimleri, mesleki durum, beslenme, önceden geçirilmiş rahatsızlıklar ve bireysel özellikleri gibi pek çok kişisel farklılık etkilemektedir (Birol, 2011). Biyolojik ve fizyolojik gerilemelerin görülebildiği dönem olan yaşlılıkta, gelișen fizyolojik değișikliklerle beraber yaşlılar daha sık enfekte olurlar (Altın, 2020).

Tüm yaș grupları Covid-19 ile bulaşma riski altında olmakla birlikte, yaşlı bireyler yaşlanma ve altta yatan tıbbi durumları nedeni ile ciddi hastalık geçirme riskiyle karşı karşıyadır. Yaşlı bireyler hem yaşla birlikte organ ve sistemlerdeki fizyolojik ve biyolojik değișiklikler hem de altta yatan tıbbi durumlar nedeniyle Covid-19 enfeksiyonu açısından daha fazla risk altındadırlar (Mueller, McNamara \& Sinclair, 2020). Ayrıca yaşlanmış bireyin immün sisteminde klinik olarak enfeksiyonlara, otoimmünite ve maligniteye yatkınlık vardır (Ekici, 2020). Yaşlanma ile birlikte fonksiyonel kapasitede azalmalar ve kayıplar görülür (Hastaoğlu \& Hastaoğlu, 2018). Tüm bu bilgiler ışığında yaşlı nüfusun giderek arttığı ülkemizde, yașlılık ve eșlik eden kronik hastalıklar, toplum sağlığının sürdürülmesi ve korunması adına önemli bir tehdit oluşturmaktadır (Çifçili, 2012).

Yaşlı bireylerde sık görülen sağlık problemleri yașlılığın 7 i'si olarak sınıflandırılmıștır. Bunlar; bilișsel fonksiyonlarda gerileme/azalma (intellectual failure), hareketsizlik (immobility), dengesizlik (instability), idrar-gaita tutamama (incontinence), uykusuzluk (insomnia), tanı ve tedavi girişimlerinden kaynaklanan sorunlar (iatrojenik problems), ailelerin katılımı (involvement of the families)'dir (Kutsal, 2007). Covid19 pandemisi yaşlıların yaşadığı bu sağlık sorunlarını arttırabilir. Artan bu sağlık sorunları da yaşlıların psikolojik olarak yaşam doyumlarını azaltarak, depresyona neden olabilir. Yapılan bir çalıșmada yaşlıların sağlık sorunlarının olması, kronik hastalık tanısı almaları, yaşam doyumlarını etkilediği belirlenmiștir (Softa, Karaahmetoğlu, Erdoğan \& Yavuz, 2015).

\subsection{Yaşlılardaki Sosyolojik Etkilenimler}

Son yarım asrın en önemli sosyal krizi olarak isimlendirilen koronavirüs pandemisi, diğer doğal afetler ve salgınlar gibi toplumdaki hassas ve kırılgan yapıyı etkilemektedir. Giderek yașlanan Batı ülkelerinde koronavirüs pandemi sürecinde ortaya çıkan sonuçlar, sağlık sistemindeki en zayıf halkanın, yașlı ve engelli hastalar olduğunu göstermiștir. Benzer șekilde, T.C. Sağlık Bakanlığ da (2020) hastalık karşısında en çok risk altında olan grubun kronik rahatsızlığı bulunanlar ve yaşlılar olduğunu belirtmiștir. Risk altında olduğu belirtilen yașlı nüfus grubu, ülkemizdeki toplam nüfusun \% 9,1'ini oluşturmaktadır ve nüfus projeksiyonlarına göre bu oranın gittikçe yükseleceği beklenmektedir (TÜIK, 2018).
Yașam süresinin uzaması ve yașlı nüfusun artıșı göz önüne alındığında salgın sürecinin, yaşlılık kültürüne ve toplumdaki yaşlılık algısına etkisinin tespit edilmesi gerekmektedir. Salgın sürecinde yașlıların korunması ve bulaşma riskinin azaltılması için Türkiye'de Sağlık Bakanlığı tarafından birçok politika izlenmiștir (Özdemir, 2020). Pandeminin psikososyal boyutu gözden geçirildiğinde, Sağlık Bakanlığı 2019 yılı içerisinde pandemi ulusal hazırlık planı hazırlamıș, bu planda psikososyal destek için de bir eylem planı oluşturulmuştur (Sağlık Bakanlığı, 2019). Psikososyal destek eylem planlarında dezavantajlı grupların ihtiyaçlarına yönelik yapılacak güçlendirme çalıșmaları ve pandeminin potansiyel olarak etkileyebileceği özel gruplara (çocuklar, yaşlılar, kronik hastalığı olanlar, gebeler gibi) da yer verilmektedir. Sadece dezavantajlı grupların ihtiyaçları değil, karşılaşabilecekleri zorlukların toplum tarafından algılanışı da önemlidir.

Dolayısıyla salgın sürecinde risk grubunu teşkil eden yaşlı bireyler, yaşam sürdükleri kişilerin olup olmaması, ekonomik düzeyleri, eğitim seviyeleri, çevresel faktörler ve cinsiyete bağlı etkenler çerçevesinde değişiklik göstermekte ve bu nedenle de yaşlılık algısının birey ve toplum bakıș açısıyla incelenmesi gerekmektedir (Özdemir, 2020). Diğer bir deyişle ülkemizde dezavantajlı gruplarda sayılan yașlıların pek çoğunun bu süreçte, teknolojiden faydalanarak bilgiye ulaşma sürecinde de problem yașayabileceği dikkate alındığında (TV, uzaktan eğitim, HES kodu alma) toplumsal açıdan pandeminin yaşlılardaki etkilenimleri üzerinde durmak oldukça önemlidir.

Tüm bu bilgiler ıșığında, pandemi süreci toplumsal anlamda dezavantajlı grupta bulunan yaşlıların, yaşlı ayrımcılığını daha da derinleștirmiștir. Diğer bir deyișle, pandeminin ortaya çıkıșı sonrasında getirilen düzenlemeler karşıssında yaşlıların yaşadığı uyum güçlüğü, yașlıların sosyal medya üzerinde çeșitli görsel ve video paylaşımlar aracılığıyla literatürde "yaşçılık" olarak değerlendirilen ayrımcılık ve damgalamaların odağı haline gelmelerine sebep olmuştur (Kara, 2020).

\subsection{Yaşlılardaki Psikolojik Etkilenimler}

Yaşlılık dönemi, yaşlıların yaşam doyumlarında azalmaya neden olabilen önemli gelișimsel dönemlerdendir (Mollaoğlu \& Hastaoğlu, 2017) Güncel araştırmalar, sosyal izolasyon, fiziksel mesafe, sokağa çıkma yasağı gibi önlemlerin yaşlıların yalnızlaştırılmasına neden olduğunu ve buna bağlı gelișen yalnızlığın yașlılarda kaygı, depresyon, bilișsel işlev bozukluğu, kalp hastalığı ve mortalite riskini artırdığını göstermektedir (Brooke \& Jackson, 2020). Yaşlıları izole etmek, vakalarda zirveyi geciktirmek ve yüksek risk gruplarına yayılımı en aza indirmek için en önemli olan bulașmayı azaltabilir. Bununla birlikte, izolasyon stratejilerine bağlılığın zamanla azalması muhtemeldir. Bu tür hafifletme önlemleri, bulașmayı önlemek için etkili bir șekilde zamanlanmalıdır. Ancak duygusal bozukluklarla ilişkili Covid-19'un morbiditesini artırmaktan kaçınmalıdır (Armitage \& Nellums, 2020). Covid-19 salgını tüm dünyada yașam şeklini değiștirmeye zorlasa da özellikle yașlılar arasında yalnızlık ve sosyal izolasyonu değerlendirmek için stratejiler ve yaklaşımlar 
geliştirmek oldukça önemlidir (Berg-Weger \& Morley, 2020).

\section{SONUÇ VE ÖNERÍLER}

Covid-19'un dünya çapındaki yayılması endișe verici ve oldukça önemli bir halk sağllğı sorunudur. Ortaya çlkan veriler, Covid-19'un özellikle multimorbiditesi olan yașlı kișiler için özel bir risk olduğunu göstermektedir. Covid-19 enfeksiyonlarına ilişkin son raporlar, hem toplumda yașayan yașlıların hem de bakım evlerinde, yardımlı yaşam tesislerinde ve diğer toplu yaşam ortamlarında ikamet edenlerin yüksek risk altında olduğunu göstermektedir(Applegate \& Ouslander, 2020).

Sonuç olarak pandemi, başta sağlık olmak üzere psikolojik, sosyal ve ekonomik pek çok alanda insan yaşamını önemli ölçüde etkilemiştir. Covid-19 'dan etkilenen yaşlı bireylerin psikososyal gereksinimlerine (ölüm korkusu, yalnızlık, damgalanma, sosyal dışlanma ve diğer sosyal hizmetlere ulaşım) yönelik yerel uygulamaların hayata geçirilmesi gerekmektedir.

\section{KAYNAKÇA}

Altın, Z. (2020). Elderly people in Covid-19 outbreak. The Journal of Tepecik Education and Research Hospital, 30, 49-57. doi:10.5222/terh. 2020.93723

Applegate, W. B., \& Ouslander, J. G. (2020). Covid-19 Presents High Risk to Older Persons. Journal of the American Geriatrics Society, 68(4), 681-681. doi:10.1111/jgs.16426

Armitage, R., \& Nellums, L. B. (2020). Covid-19 and the consequences of isolating the elderly. The Lancet Public Health, 5(5), 256 doi:10.1016/S24682667(20)30061-X

Berg-Weger, M., \& Morley, J. E. (2020). Loneliness and Social Isolation in Older Adults during the Covid19 Pandemic: Implications for Gerontological Social Work. Journal of Nutrition, Health and Aging, 24, 456-458. doi:10.1007/s12603-0201366-8

Bilgili, N., Kitiș, Y., \& Ayaz, S. (2012). Yaşlılarda yalnızlık, uyku kalitesi ve etkileyen faktörlerin değerlendirilmesi. Turk Geriatri Dergisi, 15(1), 81-88.

Birol, L. (2011). Hemşirelik Süreci (10.Baskı). İzmir: Etki Matbaacılık.

Brooke, J., \& Jackson, D. (2020). Older people and Covid-19: isolation, risk and ageism. Journal of Clinical Nursing, 29(13-14), 2044-2046. doi:10.1111/jocn.15274

Çifçili, S. (2012). Aktif yaşlanma: Fiziksel boyut. Turkish Family Physician, 3(1), 15-22. Retrieved from www.turkishfamilyphyscian.com

Edelman, L. S., McConnell, E. S., Kennerly, S. M., Alderden, J., Horn, S. D., \& Yap, T. L. (2020). Mitigating the effects of a pandemic: Facilitating Improved Nursing Home Care Delivery Through Technology. JMIR Aging, 3(1), e20110. doi:10.2196/20110

Ekici, E. (2020). Covid-19 pandemisi sürecinde yașlı bireylerin bakım yönetimi. Haliç Üniversitesi Dergisi, 145-152.
Hastaoğlu, F., \& Hastaoğlu, E. (2018). Current problems of the elderly: Poor Nutrition. Journal of Current Researches on Health Sector, 8(1), 89-94. doi:10.26579/jocrehes_8.1.8

İçişleri Bakanlığı. (2020). 65 Yaş ve Üstü ile Kronik Rahatsızlığı Olanlara Sokağa Çıkma Yasağı Genelgesi (21 Mart 2020). https://www.icisleri. gov.tr/65-yas-veustu-ile-kronik-rahatsizligiolanlara-sokaga-cikmayasagi-genelgesi. (Erişim Tarihi: 06 Nisan 2020).

Kara, Z., \& Alsancak, F. (2020). Koronvirüs pandemisinde toplumun yașll ve engellilere yönelik düşünceleri üzerine bir araştırma. Pearson Journal of Social Sciences \& Humanities, 7(2), 1-16.

Kaya, M. (2020). Koronavirüs Salgınında Yaşlılar Nasıl Hedef Haline Geldi. SETA Perspektif, Erişim adresi https://www.setav.org/perspektif-koronavirus-salgininda-yaslilar-nasil-hedef-halinegeldi/

Kutsal, Y. (2007). Temel Geriatri. Türkiye: Güneş Tıp Kitabevleri.

Mollaoğlu, M., \& Hastaoğlu, F. (2017). Determination of the Life Satisfaction of Elderly People Living in Nursing Homes. Journal of Current Researches on Health Sector Year, 7(2), 21-28 doi:10.26579/jocrehes_7.2.2

Mueller A. L., McNamara, M. S., \& Sinclair, D. A. (2020). Why does Covid-19 disproportionately affect older people? Aging (Albany NY) .12(10), 99599981. doi:10.18632/aging.103344

Oflaz, F. (2020). Covid-19 pandemisi ve yaşlılar. Erișim tarihi: 1 Mayıs 2020, https://korona.hasuder. org.tr/Covid-19-pandemisi-ve-yaslilar/

Özdemir, M. (2020). Yaşlılık algısının koronavirüs salgını sürecindeki kültürel değișimi. Milli Folklor, 127(32), 46-58.

Qui, J., Shen, B., Zhao, M., Wang, Z., Xie, B., \& Xu, Y. (2020). "A nationwide survey of psychological distress among Chinese people in the Covid-19 epidemic: implications and policy recommendations". General Psychiatry, 33,1-3.

Sağlık Bakanlığı. (2020a). "Koronavirüs, alacağımız tedbirlerden güçlü değildir". Erişim tarihi: 1 Mayis 2020, https://www.saglik.gov.tr/TR,64383/koronavir us-alacagimiz-tedbirlerden-guclu-degildir.html

Sağlık Bakanlığı. (2020b). "Covid-19 enfeksiyonunda kimler daha fazla risk altında?". Erișim tarihi: 2 Mayls 2020, https://covid19bilgi.saglik. gov.tr/tr/covid19-kimler-risk-altinda

Softa, H. K., Karaahmetoğlu, G. U., Erdoğan, O., \& Yavuz, S. (2015). Yaşlılarda yaşam doyumunu etkileyen bazı faktörlerin incelenmesi. Yaşlı Sorunları Araştırma Dergisi, 8(1), 12-21.

TUIK, (2018). İstatistiklerle Yaşlılar. Erişim adresi https://hsgm.saglik.gov.tr/depo/birimler/ kronik-hastaliklar-engellidb/hastaliklar/Yasli Sagligi/raporlar_istatistikler/TUIK_Yasli_ Istatistik 2018.pdf 
Türkiye Bilimler Akademisi. (2020). Covid-19 Pandemi Değerlendirme Raporu. Tüba raporları, 17 Nisan 2020

Velavan, T. P., \& Meyer, C. G. (2020). The Covid-19 epidemic. Tropical Medicine and International Health, 25(3), 1-3. doi:10.1111/tmi.13383.

WHO (2020). World Health Organisation. Retrieved December 5, 2020, from https://www.euro. who.int/en/health-topics/health-emergencies/ coronavirus-covid-19/weekly-surveillancereport,2020, (eri\%3C015F\%)

WHO (2020). Covid-19 Strategy Update Report. Retrieved from https://www.who.int/ publications-detail/covid-19-strategy-update

WHO (2020). Summary Report on Proceedings Minutes and Final Acts of The International Health Conference, New York. Retrieved from https://apps.who.int/iris/handle/10665/ $\underline{85573}$

Zhou, P., Yang, X. L, Wang, X. G., Hu, B., Zhang, L., Zhang, W., .... Shi, Z. L. (2020). A pneumonia outbreak associated with a new coronavirus of probable bat origin. Nature, 559, 270-289. doi:10.1038/ s41586-020-2012-7 